\title{
Spatial and temporal distribution patterns of tick-borne diseases (Tick-borne Encephalitis and Lyme Borreliosis) in Germany
}

\author{
Sarah Cunze ${ }^{\text {Corresp., } 1}$, Gustav Glock $^{1}$, Sven Klimpel ${ }^{1,2}$ \\ ${ }^{1}$ Institute of Ecology, Evolution and Diversity, Johann Wolfgang Goethe Universität Frankfurt am Main, Frankfurt am Main, Hesse, Germany \\ 2 Biodiversity and Climate Research Centre, Senckenberg Nature Research Society, Frankfurt am Main, Hesse, Germany \\ Corresponding Author: Sarah Cunze \\ Email address: cunze@bio.uni-frankfurt.de
}

Background. In the face of ongoing climate warming, vector-borne diseases are expected to increase in Europe, including tick-borne diseases (TBD). The most abundant tick-borne diseases in Germany are TickBorne Encephalitis (TBE) and Lyme Borreliosis (LB), with Ixodes ricinus as the main vector.

Methods. In this study, we display and compare the spatial and temporal patterns of reported cases of human TBE and LB in relation to some associated factors. The comparison may help iwith the interpretation of observed spatial and temporal patterns.

Results. The spatial patterns of reported TBE cases show a clear and consistent pattern over the years, with many cases in the south and only few and isolated cases in the north of Germany. The identification of spatial patterns of LB disease cases is more difficult due to the different reporting practices in the individual federal states. Temporal patterns strongly fluctuate between years, and are relatively synchronized between both diseases, suggesting common driving factors. Based on our results we found no evidence that weather conditions affect the prevalence of both diseases.

Both diseases show a gender bias with LB bing more commonly diagnosed in females, contrary to TBE being more commonly diagnosed in males.

Conclusion. For a further investigation of of the underlying driving factors and their interrelations, longer time series as well as standardised reporting and surveillance system would be required. 


\section{Spatial and temporal distribution patterns of tick-borne} 2 diseases (Tick-borne Encephalitis and Lyme 3 Borreliosis) in Germany

5 Sarah Cunze ${ }^{1}$, Gustav Glock ${ }^{1}$, Sven Klimpel ${ }^{1,2}$

$8{ }^{1}$ Goethe-University, Institute of Ecology, Evolution and Diversity; Max-von-Laue-Str. 13, D9 60438, Frankfurt/ Main, Germany.

${ }^{2}$ Senckenberg Gesellschaft für Naturforschung, Senckenberg Biodiversity and Climate Research Centre; Senckenberganlage 25, D-60325, Frankfurt/ Main, Germany.

13

14

15

16

17
Corresponding Author:

Sarah Cunze

Max-von-Laue-Straße 13, Frankfurt am Main, Hesse, 60438, Germany

Email address: cunze@,bio.uni-frankfurt.de 


\section{Abstract}

23 Background. In the face of ongoing climate warming, vector-borne diseases are expected to 24 increase in Europe, including tick-borne diseases. The most abundant tick-borne diseases (TBD) 25 in Germany are Tick-Borne Encephalitis (TBE) and Lyme Borreliosis (LB), with Ixodes ricinus 26 as the main vector.

27 Methods. In this study, we display and compare the spatial and temporal patterns of reported cases of human TBE and LB and in relation to some associated factors. The comparison may help in the interpretation of observed patterns in recorded human cases.

Results. The spatial patterns of reported TBE cases show a clear and consistent pattern over the 31 years, with many cases in the south and only few and isolated cases in the north of Germany. The identification of spatial patterns of LB disease cases is more difficult due to the different reporting practices in the individual federal states. Temporal patterns strongly fluctuate between years, and are relatively synchronized between both diseases, suggesting common driving factors. Both diseases show a gender bias, with LB being more commonly diagnosed in females, contrary to TBE being more commonly diagnosed in males. Based on our results, we found no evidence that

37 weather conditions affect the prevalence of the two diseases.

38 Conclusion. For a further investigation of the underlying driving factors and their interrelations, 39 longer time series as well as standardised reporting and surveillance programmes would be 40 required. 


\section{Introduction}

44 Tick-borne diseases in Europe

45 In recent years, tick populations in Europe have been observed to expand their range further north 46 to higher latitudes and altitudes (Gilbert, 2010a; Süss, 2011). This range shift has been 47 accompanied by an increase in the number of human tick-borne disease (TBD) cases (Gray et al., 48 2009; Heyman et al., 2010). However, this increase could also be due, at least in part, to better 49 diagnostics and higher awareness.

50 Ticks are competent vectors for a number of pathogens, including viruses, bacteria or parasites,

51 which can cause serious infections in humans and animals. Ixodes ricinus is the most abundant 52 and widespread tick species in Europe (Gray et al., 2009) and the primary vector for Lyme 53 borreliosis (LB) and tick-borne encephalitis (TBE), the most common diseases associated to ticks 54 in Europe (Semenza \& Suk, 2018).

55 Lyme borreliosis, also known as Lyme disease, is caused by bacteria of the Borrelia burgdorferi 56 sensu lato complex, which comprises about 20 members; six of them are confirmed to be human 57 pathogens (Lin et al., 2020). With approximately 65,000 cases per year, LB is the most frequent 58 tick-borne disease in the European Union (RKI 2020).

59 TBE is a viral infection caused by one of three tick-borne encephalitis virus subtypes belonging to 60 the Flaviviridae family; over the last 30 years, a large increase of nearly $400 \%$ in the number of 61 recorded cases has been observed worldwide (Fong, 2020). Although this increase can be partly 62 explained by enhanced surveillance and diagnostic TBE should be considered a growing public

63 health challenge in Europe and other parts of the world (Medlock et al., 2013).

64 Both pathogens are transmitted to humans through the bite of infected ticks. 
66 Ixodes ricinus, the primary vector of TBE and LB in Europe, is a three-host tick: After hatching

67 from the egg, there are three distinct stages (larva, nymph, adult) in the life cycle. Each passage,

68 from larva to nymph as well as from nymph to adult stage, requires a blood meal before the 69 subsequent moult. Ticks only feed once per life stage (larva, nymph and adult female). After the 70 blood-sucking process, that takes about 2-4 days for larvae and 3-5 days for nymphs, the tick 71 detaches and develops in the vegetation (moulting) (Gray, 1998). After mating and another blood 72 meal (duration of about 6-10 days) the female adults tick lays a batch of between 1000 and 5000 73 eggs and then dies (Süss, 2003). The average timespan of each stage is approximately 8-12 months 74 but can be extended to two up to six years (Gray, 1998; Stanek et al., 2012). Under favourable 75 environmental conditions ticks are able to survive for several months without feeding (Heyman et 76 al., 2010).

77 Like most ectothermic terrestrial organisms, the development and activity of ticks depend on 78 weather and climatic conditions. Ixodes ricinus ticks may enter a prolonged behavioral or 79 developmental diapause when hosts are not available or environmental conditions are unsuitable 80 for the ticks (Gray, 1998; Heyman et al., 2010). The activity phase begins when temperatures rise 81 to a certain level in spring (to 5 to $7^{\circ} \mathrm{C}$, i.e. March / April according (Süss, 2003) and ends when it 82 gets too cold in late autumn or winter. Other factors, such as summer drought, can regionally lead 83 to reduced tick activity. Mild winters or in thermally favoured regions can lead to activity during 84 the winter (Dautel et al., 2008).

85 The host spectrum of $I$. ricinus comprises more than 300 vertebrate species (wild and domestic 86 mammals, reptiles and birds). Preferred host species differ between the life stages (Stanek et al., 87 2012): The larvae feed on animals of all sizes (Süss, 2011), particularly small mammals, birds and 
88 reptiles, nymphs feed on medium-sized mammals such as foxes but also on birds and humans

89 (Süss, 2011). The adult stage feeds more exclusively on larger mammals such as deer, sheep, dogs

90 and humans (Medlock et al., 2013).

91 Ixodes ricinus shows an exophilic (non-nidicolous) behaviour in all stages, i.e. individuals do not

92 live in or near the shelters used by their vertebrate hosts. Preferred habitats are all woodlands,

93 especially deciduous forests and the transition zones between forests and grasslands (Estrada-

94 Peña, Mihalca \& Petney, 2018). Ixodes ricinus occurs throughout a large part of continental

95 Europe and the species is assumed to be nearly omnipresent in Germany (Estrada-Peña, Mihalca

$96 \&$ Petney, 2018; ECDC, 2019).

97 Transmission cycle

98 Borrelia burgdorferi bacteria and the TBE viruses circulate between I. ricinus individuals and their

99 vertebrate hosts. Ticks become infected when they feed on birds or mammals that carry the

100 pathogens in their blood and may transmit the pathogens with the following blood meal to the next

101 host (Stanek et al., 2012). Adult ticks usually feed on larger animals such as deer, which are not a

102 reservoir for $B$. burgdorferi bacteria, but help to maintain the ticks' reproductive stage $(E C D C$,

103 2020). The main reservoir hosts of TBE virus are mainly small rodents, e.g. voles and mice, but

104 also insectivores and carnivores $(C D C, 2020 ; E C D C, 2020)$. Ticks, specifically hard ticks of the

105 family Ixodidae, act as both the vector and reservoir for TBE viruses $(C D C, 2020)$.

106 Transmission of B. burgdorferi to humans occurs through a bite from an infected tick, in most

107 cases by a tick in the nymph stage (Gray, 1998). Being more numerous than adult ticks, nymphal

108 ticks are responsible for approximately $80 \%$ of tick bites in many areas (Heyman et al., 2010) and,

109 thus, we may expect them to cause most of LB cases. Larval tick bites do not pose a significant

110 risk because larvae rarely carry infection (Gray et al., 1998). In field collections less than 1\% of 
111 host seeking larvae have been found to be infected with B. burgdorferi (Hofhuis et al., 2017) which

112 may be attributed to transovarial transmission (Humair \& Gern, 2000).

113 Infected ticks are unlikely to transmit the B. burgdorferi s.l. in the early hours of a feed, but the

114 risk rises steadily the longer the blood meal takes; so early removal of attached ticks within the

115 first hours is very useful in reducing transmission risk (ECDC, 2014).

116 In contrast, the TBE virus can even be transmitted from the saliva of an infected tick within the

117 first minutes of the bite (Lindquist \& Vapalahti, 2008).

118 Factors affecting the number of human tick-borne disease cases

119 The risk of human infection by TBDs depends on many environmental factors and their 120 interactions, affecting both the ecology of the pathogens and that of the vectors and reservoir hosts 121 (Süss, 2003). The number of TBD cases in humans thus primarily depends on the abundance of 122 tick species, the frequency of contact between humans and ticks and the prevalence of the 123 pathogens. The higher the number of ticks, the higher the risk for humans to be bitten; the higher 124 the prevalence of pathogens, the higher the risk of becoming infected through a tick bite 125 (Randolph, 2008; Pfäffle et al., 2013; Wikel, 2018; Escobar, 2020).

126 The abundance of ticks depends on climatic and weather conditions (e.g., mild winters favour a 127 high abundance in the following season), land cover (e.g. higher abundances in forested areas) and 128 the abundance of hosts (e.g. small rodents, birds, red deer and wild boars) (Randolph, 2008; 129 Jaenson \& Lindgren, 2011; Jaenson et al., 2012; Medlock et al., 2013). Temperature can also have 130 a direct impact on the transmission risk of pathogens as it influences reproduction of pathogens in 131 ectothermal vector species. Thus, it is assumed that higher temperatures have a direct effect on the 132 risk of infection with tick-borne diseases (Samuel, Adelman \& Myles, 2016). 
133 There are several interactions between the components that influence the risk for humans of

134 becoming infected with tick-borne pathogens (Figure 1). The prevalence of TBD agents in ticks 135 also depends on the availability of hosts and the prevalence of TBD agents in hosts. In particular, 136 it is assumed that the abundance of small rodents depends on the availability of food (depending 137 on the fructification of forest trees) and weather conditions (Klempa, 2009; Reil et al., 2015). In 138 spatial terms, land cover may play an important role (e.g. forest cover) (Randolph, 2010; Pfäffle 139 et al., 2013). Human behaviour depends on the weather situation and on land cover (Randolph, 140 2010):People spend more time outside in good weather than in bad weather and forested regions 141 may be more crowded than other land cover types. For TBE, vaccination coverage is also an 142 important factor (Randolph, 2008).

\section{Aims and scopes}

144 In this study, we display the spatial and temporal (annual and seasonal) patterns of LB and TBE 145 based on the data provided by the Robert-Koch-Institute (RKI) between 2001 and 2019. We 146 discuss and compare these patterns considering possible underlying drivers: climatic and weather 147 conditions and other factors (see Figure 1).

150 We tried to link additional data with the spatial and temporal patterns of the reported cases of the 151 two tick-borne diseases in Germany. All maps are based on data downloaded from various 152 databases, and data covered the following variables:

a) Data on reported cases of LB and TBE (from hereon after "reported cases" refers to human cases only) was downloaded at a spatial level of German administrative districts (German: 
"Landkreise") for the years 2001 to 2019 with a temporal resolution of one calendar week (Robert Koch-Institut: SurvStat@RKI 2.0, https://survstat.rki.de, query date: 03.02.2020) and mapped using the geometry of NUTS250 (Nomenclature des unités territoriales statistiques) data provided by the German Federal Agency for Cartography und Geodesy (GeoBasis-DE / BKG (2020)) and using ESRI ArcGIS software (ESRI, 2018).

b) Data on population numbers in each of the German administrative districts were taken from the German Federal Agency for Cartography und Geodesy (GeoBasis-DE / BKG (2020) status of the documentation 01.12.2017, accessed on 02.03.2020).

c) Occurrence records for Ixodes ricinus as the major vector of TBE and LB were taken from the Global Biodiversity Information Facility (GBIF) data base (www.GBIF.org, DOI: https://doi.org/10.15468/dl.yak5vd (GBIF), accessed on 23.06.2020). We also used information of the currently known distribution of $I$. ricinus by administrative districts based on data from the European Centre for Disease Prevention and Control (ECDC, 2019).

d) Taking the wild boar (Sus scrofa) as one example of an important host species, we used data on its spatial distribution at the level of administrative districts (Nuts3 units), more specifically, the number of reported individuals (hunted and roadkill) per 100 ha of hunting area in the respective administrative district. The data was compiled by the German Hunting Association (Deutscher Jagdverband DJV) as part of the WILD monitoring (DJV, 2020). We chose the wild boar as a representative of a large host of ticks because of data available and because we assume that other medium and large forest-associated hosts (roe deer, red deer, red fox...) of ticks show similar ecological requirements and therefore 176 similar distribution patterns (see also below - h). 
177 e) Data on temperature and precipitations patterns in Germany was taken from the German

178

179

180

181

182

183

184

185

186

187

188

189

190

191

192

193

194

195

196

197

198 Meteorological Service (Deutscher Wetterdienst DWD). We considered the mean annual temperature and precipitation, both averaged over the empirical data from 1981 to 2010 per grid cell $(1 \mathrm{~km} \times 1 \mathrm{~km})$ for spatial patterns, and the mean monthly mean air temperature and precipitation from 2001 to 2019 for temporal patterns.

f) The percentage of forest area in each German administrative district was derived from the Corine landcover data $(C L C 2012,2012)$ provided by the Copernicus Land Monitoring Service, coordinated by the European Environment Agency (EEA) and includes deciduous forest, coniferous forest and mixed forest (3.1.1, 3.1.2, 3.1.3).

g) Data on beech mast stem from reports on the state of the forests (in German: "Waldzustandberichte") of individual German federal states. Since the data are not available for all federal states over the entire period, the values of the federal states BadenWuerttemberg $(W Z B, 2018 \mathrm{a})$, Bavaria $(W Z B, 2019 \mathrm{a})$, Brandenburg $(W Z B, 2018 \mathrm{~b})$, Hesse $(W Z B, 2019 b)$ and Saxony $(W Z B, 2019 c)$ were averaged for each year between 2002 and 2019. Despite observed smaller regional differences in beech mast (Reil et al., 2015), it is generally assumed that mast years are largely driven by weather conditions that have occurred in previous years in combination with refractory periods to accumulate resources (Piovesan \& Adams, 2001; Overgaard, Gemmel \& Karlsson, 2007; Cunze et al., 2018). We therefore argue that the averages of the empirical data from the above mentioned five federal states are a good measure for the average situation in Germany.

h) Occurrence data for selected small rodents (main hosts for ticks in larval and nymph stages), medium and large mammals (main hosts for adult ticks and important dispersal 

ticks) were taken from GBIF (www.GBIF.org, GBIF, 2021).

201 A map including names of federal states and single administrative districts is given in the appendix 202 (Figure S1). All maps were generated using Esri ArcMap, version 10.8.1. 
204 Results

205 Spatial patterns of reported TBE and LB disease cases in Germany 2001-2019

206 The spatial distribution of the incidence (reported cases per 100,000 inhabitants) of TBE in

207 Germany (Figure 2) shows a very similar pattern for all years between 2001 and 2019, with a 208 larger number of cases in the south of Germany and far fewer cases in the north. In the north, no 209 cases have been reported in the majority of German administrative district, whereas up to 13 210 cases per 100,000 inhabitants have been reported from administrative districts in the south, with 211 the highest number of cases located in the federal states Bavaria and Baden-Wuerttemberg, 212 South Hesse, South-East Thuringia and Saxony. Generally, the number of recorded TBE cases 213 seems to increase over time and individual districts seem to be particularly affected but without a 214 temporal pattern. 
215 The spatial pattern of LB infections over time in Germany is depicted in Figure 3. In many federal 216 states, the obligation to report LB infections was first introduced in the period between 2001 and 2172019 (e.g. Saarland and Rhineland-Palatinate in 2011 and Bavaria in 2016) or is still not in place 218 (e.g. Baden-Württemberg, Hesse, North Rhine-Westphalia, Lower Saxony and Schleswig219 Holstein) and explains the large amount of grey area with no available data on LB cases. Due to 220 the different regulations on reporting obligations in the federal states of Germany, spatial patterns 221 are difficult to assess. Considering areas with existing reporting obligations, there are no clear 222 patterns such as gradients or hotspots.

223

224 With regard to factors assumed to influence the spatial patterns of tick-borne disease occurrence, 225 we have mapped spatial patterns in the occurrence of each component in the transmission cycle 226 (humans, Ixodes ricinus as the main vector species and wild boar density, representing the 227 occurrence of hosts) and several relevant environmental factors (precipitation, temperature and 228 forest cover).

229

Figure 4 may help to interpret the spatial patterns of the human infections with TBE and LB. (Since 230 there is no nationwide reporting obligation for LB in Germany, we have only shown the mean data for the six federal states in which there has been a continuous reporting obligation since 2002 in 232 Figure 4b.)

233 For example, the district Sächsische Schweiz Osterzgebirge in the south of Saxony (cf. Figure 234 S1), which has a high total number of reported LB cases in the period 2002 to 2019 (4116 cases, 235 Figure 4b), is characterized by a relatively high population density (Figure 4c), average wild boar 236 density (Figure 4e) and rather low forest cover (Figure 4h). Temperatures are also comparatively 237 low with a lot of precipitation (Figure $4 \mathrm{f}, \mathrm{g}$ ). On the other hand, the hotspot for LB in 2016 and 2382018 for LB in eastern Bavaria (Figure 3) in the administrative districts Regen and Freyung239 Gravenau (cf. Figure S1). These two districts are characterized by a low population density 240 (Figure 4c), a high proportion of forest (Figure 4h) and a relatively low density of wild boar (Figure 
2414 e). Ticks were reported from these areas (Figure 4d). The temperatures are comparatively low 242 with high precipitation (Figure 4f,g).

243 The North-South gradient in the number of human TBE infections in Germany (Figure 2) is not 244 reflected by any of the factors displayed in Figure $4 \mathrm{c})$-h).

245

246 In the temporal patterns, the numbers of reported cases of TBE (Fig. 5a) and LB (Fig. 5a) show 247 seasonal variations with low numbers of cases in the winter months. It can be seen, for example, 248 that 2012 with remarkably low numbers of recorded cases for both diseases (Fig. 5a,b,c,d) was 249 preceded by four winters with very low temperatures in winter (Fig. 5e). The year 2018 with 250 comparably high numbers of recorded cases for both diseases (Fig. 5a,b,c,d) was preceded by 251 two cold winters (Fig. 5e) but also a strong beech mast year in 2017 (Fig. 5g). Overall, the 252 temperature conditions cannot be clearly related to the temporal patterns in the reported TBD 253 cases. For precipitation (Fig. 5f) it is also difficult to link the temporal patterns.

254 In the period under consideration, 2002 to 2019 , no significant trend could be observed in the 255 annually reported case numbers for TBE and a slightly positive, significant trend ( $p$-value = 256 0.02402) in the reported LB numbers (all cases reported in the six eastern German federal states:

257 Brandenburg, Berlin, Mecklenburg-Vorpommern, Saxony, Saxony-Anhalt and Thuringia).

258 However, there are strong fluctuations between years. The annual fluctuations of both diseases 259 move in parallel. A clear correlation of disease cases of TBE and LB can be seen when looking 260 at annual and monthly resolution (Fig. 6). Years with a high number of TBE cases also show high 261 numbers in LB cases and vice versa. When looking at the monthly data, an even stronger 262 correlation becomes apparent, which is partly due to the similar seasonal patterns. 
264 The gender distribution of both TBDs cases, shows consistent patterns across different age groups

265 for LB (Figure 7a): with higher incidences for females in the age categories 30-39, 40-49, 50-59, 266 60-60 and 70-79 years and for TBE (Figure 7b): higher incidences for males in all age groups.

\section{Discussion}

269 Ticks are important disease-transmitting vectors. Vector-borne diseases are on the rise in Europe, 270 which has been attributed to climate-change induced range shift of the tick vectors. Here we 271 described the spatial and temporal patterns of human TBE and LB cases in Germany in relation to 272 possible underlying drivers. There are many factors assumed to affect the spatial-temporal patterns 273 of human tick-borne diseases and their interrelationships are complex.

274 We found the temporal patterns to fluctuate strongly between years, and the patterns for both 275 diseases are relatively synchronized. The strong connection between the numbers of cases of both 276 diseases in the temporal patterns suggest that similar driving forces are involved. The presence of 277 I. ricinus as the main vector of both diseases in Europe is the key determinant for the incidence of 278 both diseases.

279 The temporal and spatial patterns presented in this study are considered typical for both diseases 280 and are in accordance with those shown in studies in other European countries (e.g. Daniel et al., 281 2008; Randolph, 2010; Moore et al., 2014). The occurrence of both diseases is highly seasonal. 282 The seasonal patterns with a peak in summer and a subsequent decline to nearly zero in the winter 283 months in the reported TBE cases and only to a few LB cases are clearly attributed to the annual 284 cycle of the ticks with a diapause in winter and questing behaviour during their activity phase. This 285 is obvious, as the diseases cannot be transmitted without blood-sucking ticks (apart from a small 
286 number of TBE cases associated with the consumption of raw milk). In addition, small mammals

287 that act as hosts are also almost inactive during the winter months.

288 The seasonal patterns of reported cases of both diseases are very similar with a slightly earlier peak 289 for TBE whose German name translates to "Early Summer Meningoencephalitis"). Randolph, 2902010 reports that the seasonal patterns in the activity of questing nymphs show a similar pattern, 291 but with peaks spared again towards earlier times of the year. This could generally be explained 292 by the incubation time and delay in reporting (RKI, 2007).

293 The fact that the number of reported LB cases does not reduce to zero in winter despite the assumed 294 inactivity of the transmitting ticks can be attributed on the one hand by a delayed diagnosis. On 295 the other hand, increased tick activity during the winter months is reported (Dautel et al., 2008), 296 which may be due to changed climatic conditions, especially milder winter temperatures in the 297 northern hemisphere (Gray et al., 2009). It is also expected that warmer and drier summers could 298 also affect the seasonal patterns in tick activity and hence the seasonal patterns in the occurrence 299 of the associated diseases (Gray et al., 2009).

300 There is a high variation between years, in which the tick-borne diseases occur more frequently 301 and years with comparatively low numbers of reported cases. It is of great interest to understand 302 the underlying factors driving this fluctuation and to be able to estimate in advance whether high 303 numbers of cases are to be expected in the current year.

304 There is no doubt that climatic and weather conditions impact tick activity and thus the temporal 305 patterns of tick-borne diseases (Moore et al., 2014). Ticks are known to be very sensitive to 306 temperature and humidity, their requirements and sensitivities differ between the stages of the life 307 cycle which leads to temperature and humidity conditions influencing tick population dynamics, 308 demographic processes and phenology regarding activity and questing behaviour (Moore et al., 
309 2014). Development rates of ticks are favoured by warmer temperature. Cold winter temperatures

310 and persistent drought in summer are considered to be stress factors for ticks and can lead to

311 reduced abundances in years following a cold winter and to reduced activity during dry summers

312 (Gray et al., 2009). In this context, Bennet, Halling \& Berglund, (2006) reported an increased

313 incidence of LB cases after mild winters and during humid and warm summers in southern

314 Sweden.For Germany, we did not find evidence for a clear correlation between the number of

315 human TBD cases and climatic or weather conditions, which is probably due to the complexity of

316 all underlying associations and factors. Besides the obvious impact of weather and climatic

317 conditions, there are important non-entomologic factors impacting the occurrence of tick-borne

318 disease in humans. So, human behaviour, which may favour the contact rates between questing

319 ticks and humans, is regarded as a key factor. Here, climatic or weather factors can also play an

320 indirect role, as favourable weather conditions promote outdoor activities such as mushroom

321 picking (Daniel et al., 2008). Outdoor activities also depend on spatial factors such as forested area

322 or attractive, touristically developed areas.

323 We found a clear pattern that LB tends to be diagnosed more often in women than in men (Figure

324 7a). TBE, on the other hand, is more common in men than in women (Figure 7b). Similar patterns

325 can be found in other countries (e.g. Zöldi et al., (2013) in Hungary and Sun et al., (2017) for TBE

326 in China) but also different patterns (e.g Bacon et al. (2008) for the United States).

327 In the case of TBE, the vaccination coverage has an important impact. Vaccination is

328 recommended for people in risk areas and for people who are exposed to an increased risk due to 329 their activities (e.g. forest workers). Vaccination coverage varies strongly between regions (RKI, 330 2020) and ranged in TBE risk areas in the German Federal States Bavaria, Baden Wurttemberg, 331 Hesse and Thuringia from $20 \%-41 \%$ for children at school entry (Hellenbrand et al., 2019). It is 
332 assumed that the proportion of vaccinated children is higher than the proportion of vaccinated

333 adults ( $>15$ years RKI, 2020) but data are currently only available for children at school entry

334 (Hellenbrand et al., 2019).

335

336 The significant slightly positive trend in TBE case numbers found by Hellenbrand et al., (2019)

337 for the period 2001 to 2018 could not be confirmed in our study for the period 2002 to 2019 , which

338 could be due to the slight decrease in case numbers for 2019. However, to derive reliable evidence

339 for the promotion of tick-borne diseases in Germany due to climate change, longer time series

340 would be required, as well as a standardised reporting and surveillance system. Regarding the

341 number of reported LB cases, a slightly positive trend can be seen. However, this can be attributed

342 in particular to the increase in the period 2002 to 2006 , a period in which the reported numbers are

343 subject to additional uncertainties typical of the initial phase of reporting practice. In general, it

344 can be assumed that the number of reported LB cases significantly underestimates the actual

345 number of cases (RKI, 2007; Palmieri et al., 2013). After an initial phase of a surveillance program,

346 the awareness of the population and the diagnostic experience of the medical staff increases over

347 time $(R K I, 2007)$.

348

349 With regard to the spatial but also to the temporal patterns of tick-borne diseases, distribution 350 patterns of host species are of major importance. The most important reservoirs are mice and birds.

351 Voles seem to play an important role as reservoir hosts for TBE, as the virus appears to be well 352 adapted to voles (Zöldi et al., 2015). In addition, other animals such as reptiles, hedgehogs, foxes

353 or rabbits are also regarded as host animals and pathogen reservoirs. In this context, the

354 fructification of forest trees can be considered as a potential driver for temporal fluctuations in the 
355 abundance of hosts, ticks and consequently the incidences of TBE and LB. A high amount of fruit 356 means a good nutritional basis and thus higher abundance for host species such as roe deer, red 357 deer, wild boar and mice. Ostfeld, Jones \& Wolff, (1996) reported an increase in nymph abundance 358 of Ixodes scapularis two years after heavy fructification in North America. Distributional patterns 359 of larger host species like dears are also affected by alternating grazing supply, hunting pressure 360 and, in Germany increasingly, by wolf occurrence. Tick abundance has been positively associated 361 with deer abundance (Gilbert, 2010b). We exemplarily displayed occurrence records of three small 362 tick hosts (Myodes glareolus, Apodemus flavicollis and shrews of the Soricidae family, Fig. S2), 363 larger tick hosts (Capreolus capreolus, Cervus elaphus and Vulpes vulpes, Fig. S3) and migratory 364 birds (Grus grus, Ciconia ciconia and Turdus merula, Fig. S4). A pattern of these species' 365 distributions that explains the spatial patterns in tick-associated diseases does not seem obvious. 366 The distribution pattern of the mammals may be similar to the distribution of the forest areas (Fig. 367 4h). However, all the maps with observed occurrences provided by GBIF of the here considered 368 species slightly show a coincident pattern with a clustering of points e.g. along the Rhine river 369 (south-western Germany). This could also indicate a certain sampling bias, that in these areas the 370 number of reports is generally higher.

371 Regarding spatial dispersal patterns, birds and particularly migratory birds may be of particular 372 importance. Migratory birds have been found to carry not only ticks but also TBD infected ticks 373 (Hasle et al., 2009; Hasle, 2013). They thus not only serve as hosts for ticks and reservoir hosts 374 for TBD pathogens (Wilhelmsson et al., 2020) but can also play an important role as potential long375 distance dispersal vectors for ticks and pathogens. Attached to birds, ticks and associated 376 pathogens can cover large distances, cross geographic barriers (e.g. rivers, oceans and mountains), 377 and possibly be introduced into new areas (Hasle, 2013). Detailed data on resting places of 
378 migratory birds in Germany are poorly available. However, for example the regions rich in lakes

379 in eastern Germany are considered as breeding places for e.g. cranes. No increased incidence of

380 TBD cases could be detected in these areas, nor could clear correlations between TBD distribution

381 and the distribution patterns of selected bird species (Fig. S2-S4) be identified. In Germany, the

382 blackbirds (Turdus merula) are considered to be one of the most important species for harbouring

383 ticks (Klaus et al., 2016). This species is very common and widespread in Germany.

384

385 To conclude, the interactions and interrelationships are complex. For further investigation of the

386 underlying driving factors and their interrelationships to achieve better risk assessment, longer

387 time series and standardized reporting and monitoring programs would be valuable. 
389

390

391

392

393

394

395

396

397

398

399

400

401

402

403

404

405

406

407

408

409

410

411

412

\section{References}

Bennet L, Halling A, Berglund J. 2006. Increased incidence of Lyme borreliosis in southern Sweden following mild winters and during warm, humid summers. European journal of clinical microbiology \& infectious diseases : official publication of the European Society of Clinical Microbiology 25 (7):426-432.

CDC. 2020. Tick-borne Encephalitis (TBE).

CLC 2012. 2012. Copernicus Land Monitoring Service referring to land cover / land use status of year 2012 .

Cunze S, Kochmann J, Kuhn T, Frank R, Dörge DD, Klimpel S. 2018. Spatial and temporal patterns of human Puumala virus (PUUV) infections in Germany. Peerj 6:e4255.

Daniel M, Kř́iž B, Danielová V, Beneš Č. 2008. Sudden increase in tick-borne encephalitis cases in the Czech Republic, 2006. International Journal of Medical Microbiology 298:81-87.

Dautel H, Dippel C, Kämmer D, Werkhausen A, Kahl 0. 2008. Winter activity of Ixodes ricinus in a Berlin forest. International Journal of Medical Microbiology 298:50-54.

DJV. 2020. Wildschwein (Sus scrofa): Durchschnittliche Jagdstrecke der Jagdjahre 2010/11 bis $2013 / 14$

ECDC. 2014. Lyme Borreliosis in Europe.

ECDC. 2019. Ixodes ricinus - current known distribution: January 2019.

ECDC. 2020. Factsheet about tick-borne encephalitis (TBE).

Escobar LE. 2020. Ecological Niche Modeling: An Introduction for Veterinarians and Epidemiologists. Frontiers in veterinary science 7:519059.

ESRI. 2018. ArcGIS. Redlands, CA: Environmental Systems Research Institute.

Estrada-Peña A, Mihalca AD, Petney TN. 2018. Ticks of Europe and North Africa: A Guide to Species Identification. Cham: Springer. 
413 Fong IW. 2020. Current Trends and Concerns in Infectious Diseases. Cham: Springer International

414 Publishing; Springer.

415 GBIF GBIF.org Occurrence Downloads:

416 Apodemus flavicollis: https://doi.org/10.15468/dl.p4r693 (01 June 2021),

417 Capreolus capreolus: https://doi.org/10.15468/dl.wp98ts (28 May 2021),

418 Cervus elaphus: https://doi.org/10.15468/dl.72ddmz (28 May 2021),

419 Ciconia ciconia: https://doi.org/10.15468/dl.k6jv69 (28 May 2021),

420 Soricidae https://doi.org/10.15468/dl.czyyq2 (01 June 2021),

$421 \quad$ Grus grus: https://doi.org/10.15468/dl.j4fe7k (28 May 2021),

422 Ixodes ricinus: https://doi.org/10.15468/dl.yak5vd (23 June 2020),

423 Myodes glareolus: https://doi.org/10.15468/dl.82wsgb (01 June 2021),

424 Turdus merula: https://doi.org/10.15468/dl.t3h8b4 (28 May 2021),

425 Vulpes vulpes: https://doi.org/10.15468/dl.wgtneb (28 May 2021)

426 Gilbert L. 2010a. Altitudinal patterns of tick and host abundance: a potential role for climate 427 change in regulating tick-borne diseases? Oecologia 162 (1):217-225.

428 Gilbert L. 2010b. Altitudinal patterns of tick and host abundance: a potential role for climate 429 change in regulating tick-borne diseases? Oecologia 162 (1):217-225.

430 Gray JS. 1998. Review the ecology of ticks transmitting Lyme borreliosis. Experimental \& applied $431 \quad$ acarology 22 (5):249-258.

432 Gray JS, Dautel H, Estrada-Peña A, Kahl O, Lindgren E. 2009. Effects of climate change on ticks 433 and tick-borne diseases in Europe. Interdisciplinary perspectives on infectious diseases $434 \quad 2009: 593232$.

435 Gray JS, Kahl O, Robertson JN, Daniel M, Estrada-Peña A, Gettinby G, Jaenson T, Jensen P, 436 Jongejan F, Korenberg E, Kurtenbach K, Zeman P. 1998. Lyme Borreliosis Habitat 437 Assessment. Zentralblatt für Bakteriologie 287 (3):211-228. 
438 Hasle G. 2013. Transport of ixodid ticks and tick-borne pathogens by migratory birds. Frontiers in $439 \quad$ cellular and infection microbiology 3:48.

440 Hasle G, Bjune G, Edvardsen E, Jakobsen C, Linnehol B, Røer JE, Mehl R, Røed KH, Pedersen J, 441 Leinaas HP. 2009. Transport of ticks by migratory passerine birds to Norway. The Journal of $442 \quad$ Parasitology 95 (6):1342-1351.

443 Hellenbrand W, Kreusch T, Böhmer MM, Wagner-Wiening C, Dobler G, Wichmann O, Altmann 444 D. 2019. Epidemiology of Tick-Borne Encephalitis (TBE) in Germany, 2001²018. Pathogens 445 (Basel, Switzerland) 8 (2).

446

447

448

449

450

451

452

453

454

455

456

457

458

459

460

461

462

Heyman P, Cochez C, Hofhuis A, van der Giessen J, Sprong H, Porter SR, Losson B, Saegerman

C, Donoso-Mantke O, Niedrig M, Papa A. 2010. A clear and present danger: tick-borne diseases in Europe. Expert review of anti-infective therapy 8 (1):33-50.

Hofhuis A, van de Kassteele J, Sprong H, van den Wijngaard CC, Harms MG, Fonville M, van Docters Leeuwen A, Simões M, van Pelt W. 2017. Predicting the risk of Lyme borreliosis after a tick bite, using a structural equation model. PloS one 12 (7):e0181807.

Humair P-F, Gern L. 2000. The wild hidden face of Lyme borreliosis in Europe. Microbes and Infection 2 (8):915-922.

Jaenson TGT, Jaenson DGE, Eisen L, Petersson E, Lindgren E. 2012. Changes in the geographical distribution and abundance of the tick Ixodes ricinus during the past 30 years in Sweden. Parasites \& vectors 5:8.

Jaenson TGT, Lindgren E. 2011. The range of Ixodes ricinus and the risk of contracting Lyme borreliosis will increase northwards when the vegetation period becomes longer. Ticks and tickborne diseases 2 (1):44-49.

Klaus C, Gethmann J, Hoffmann B, Ziegler U, Heller M, Beer M. 2016. Tick infestation in birds and prevalence of pathogens in ticks collected from different places in Germany. Parasitology research 115 (7):2729-2740. 
463

464

465

466

467

468

469

470

471

472

473

474

475

476

477

478

479

480

481

482

483

484

485

486

487

Klempa B. 2009. Hantaviruses and climate change. Clinical microbiology and infection : the official publication of the European Society of Clinical Microbiology and Infectious Diseases 15 (6):518523.

Lin Y-P, Diuk-Wasser MA, Stevenson B, Kraiczy P. 2020. Complement Evasion Contributes to Lyme Borreliae-Host Associations. Trends in parasitology 36 (7):634-645.

Lindquist L, Vapalahti 0. 2008. Tick-borne encephalitis. The Lancet 371 (9627):1861-1871.

Medlock JM, Hansford KM, Bormane A, Derdakova M, Estrada-Peña A, George J-C, Golovljova I, Jaenson TGT, Jensen J-K, Jensen PM, Kazimirova M, Oteo JA, Papa A, Pfister K, Plantard 0, Randolph SE, Rizzoli A, Santos-Silva MM, Sprong H, Vial L, Hendrickx G, Zeller H, van Bortel W. 2013. Driving forces for changes in geographical distribution of Ixodes ricinus ticks in Europe. Parasites \& vectors 6:1.

Moore SM, Eisen RJ, Monaghan A, Mead P. 2014. Meteorological influences on the seasonality of Lyme disease in the United States. The American journal of tropical medicine and hygiene 90 (3):486-496.

Ostfeld RS, Jones CG, Wolff JO. 1996. Of Mice and Mast. BioScience 46 (5):323-330.

Overgaard R, Gemmel P, Karlsson M. 2007. Effects of weather conditions on mast year frequency in beech (Fagus sylvatica L.) in Sweden. Forestry 80 (5):555-565.

Palmieri JR, King S, Case M, Santo A. 2013. Lyme disease: case report of persistent Lyme disease from Pulaski County, Virginia. International medical case reports journal 6:99-105.

Pfäffle M, Littwin N, Muders SV, Petney TN. 2013. The ecology of tick-borne diseases. International journal for parasitology 43 (12-13):1059-1077.

Piovesan G, Adams JM. 2001. Masting behaviour in beech: linking reproduction and climatic variation. Canadian Journal of Botany 79 (9):1039-1047.

Randolph SE. 2008. Tick-borne encephalitis incidence in Central and Eastern Europe: consequences of political transition. Microbes and Infection 10 (3):209-216. 
488 Randolph SE. 2010. Human activities predominate in determining changing incidence of tick-

489 borne encephalitis in Europe. Euro surveillance : bulletin Europeen sur les maladies

490 transmissibles $=$ European communicable disease bulletin 15 (27):24-31.

491 Reil D, Imholt C, Eccard JA, Jacob J. 2015. Beech Fructification and Bank Vole Population

492 Dynamics--Combined Analyses of Promoters of Human Puumala Virus Infections in Germany.

$493 \quad$ PloS one 10 (7):e0134124.

494 RKI RKI. 2007. Lyme-Borreliose: Zur Situation in den östlichen Bundesländern: Analyse der

495 Meldedaten aus dem 5-Jahreszeitraum 2001 bis 2006. Epidemiologisches Bulletin (38).

496 Samuel GH, Adelman ZN, Myles KM. 2016. Temperature-dependent effects on the replication and 497 transmission of arthropod-borne viruses in their insect hosts. Current opinion in insect science $498 \quad$ 16:108-113.

499 Semenza JC, Suk JE. 2018. Vector-borne diseases and climate change: a European perspective. $500 \quad$ FEMS microbiology letters 365 (2).

501 Stanek G, Wormser GP, Gray J, Strle F. 2012. Lyme borreliosis. The Lancet 379 (9814):461-473. 502 Sun R-X, Lai S-J, Yang Y, Li X-L, Liu K, Yao H-W, Zhou H, Li Y, Wang L-P, Di Mu, Yin W-W, Fang 503 L-Q, Yu H-J, Cao W-C. 2017. Mapping the distribution of tick-borne encephalitis in mainland 504 China. Ticks and tick-borne diseases 8 (4):631-639.

505 Süss J. 2003. Epidemiology and ecology of TBE relevant to the production of effective vaccines. $506 \quad$ Vaccine 21:S19-S35.

507 Süss J. 2011. Tick-borne encephalitis 2010: epidemiology, risk areas, and virus strains in Europe 508 and Asia-an overview. Ticks and tick-borne diseases 2 (1):2-15.

509 Wikel SK. 2018. Ticks and Tick-Borne Infections: Complex Ecology, Agents, and Host Interactions. $510 \quad$ Veterinary sciences $\mathbf{5}(\mathbf{2})$.

511 Wilhelmsson P, Jaenson TGT, Olsen B, Waldenström J, Lindgren P-E. 2020. Migratory birds as 512 disseminators of ticks and the tick-borne pathogens Borrelia bacteria and tick-borne 
513 encephalitis (TBE) virus: a seasonal study at Ottenby Bird Observatory in South-eastern

$514 \quad$ Sweden. Parasites \& vectors 13 (1):607.

515 WZB. 2018a. Waldzustandsbericht 2018.

516 WZB. 2018b. Waldzustandsbericht 2018 des Landes Brandenburg.

517 WZB. 2019a. Ergebnisse der Waldzustandserhebung 2019.

518 WZB. 2019b. Waldzustandsbericht 2019.

519 WZB. 2019c. Waldzustandsbericht 2019.

520 Zöldi V, Juhász A, Nagy C, Papp Z, Egyed L. 2013. Tick-borne encephalitis and Lyme disease in

521 Hungary: the epidemiological situation between 1998 and 2008. Vector borne and zoonotic

522 diseases (Larchmont, N.Y.) 13 (4):256-265.

523 Zöldi,V., Papp, T., Reiczigel, J., Egyed L. 2015. Bank voles and adult rodents show high

524 seropositivity rates in a natural TBEV focus in Hungary. Infectious diseases. . 47 (3) 178-181. 
Figure 1

Factors that potentially affect the number of recorded human tick-borne disease cases.

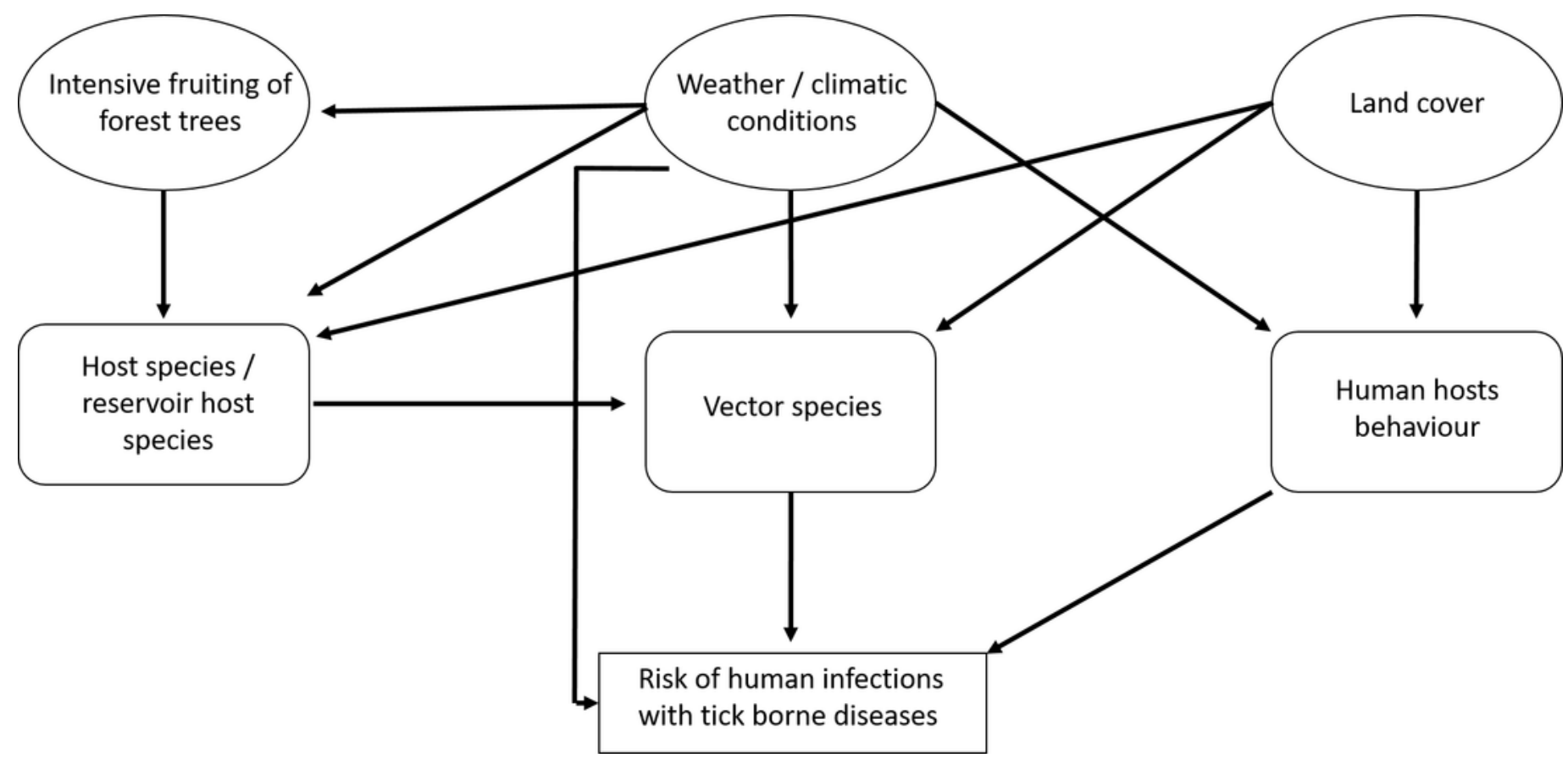


Figure 2

Spatial patterns of incidences (reported cases per 100,000 inhabitants) for tick-borne encephalitis (TBE) at the level of German administrative districts (RKI data). 


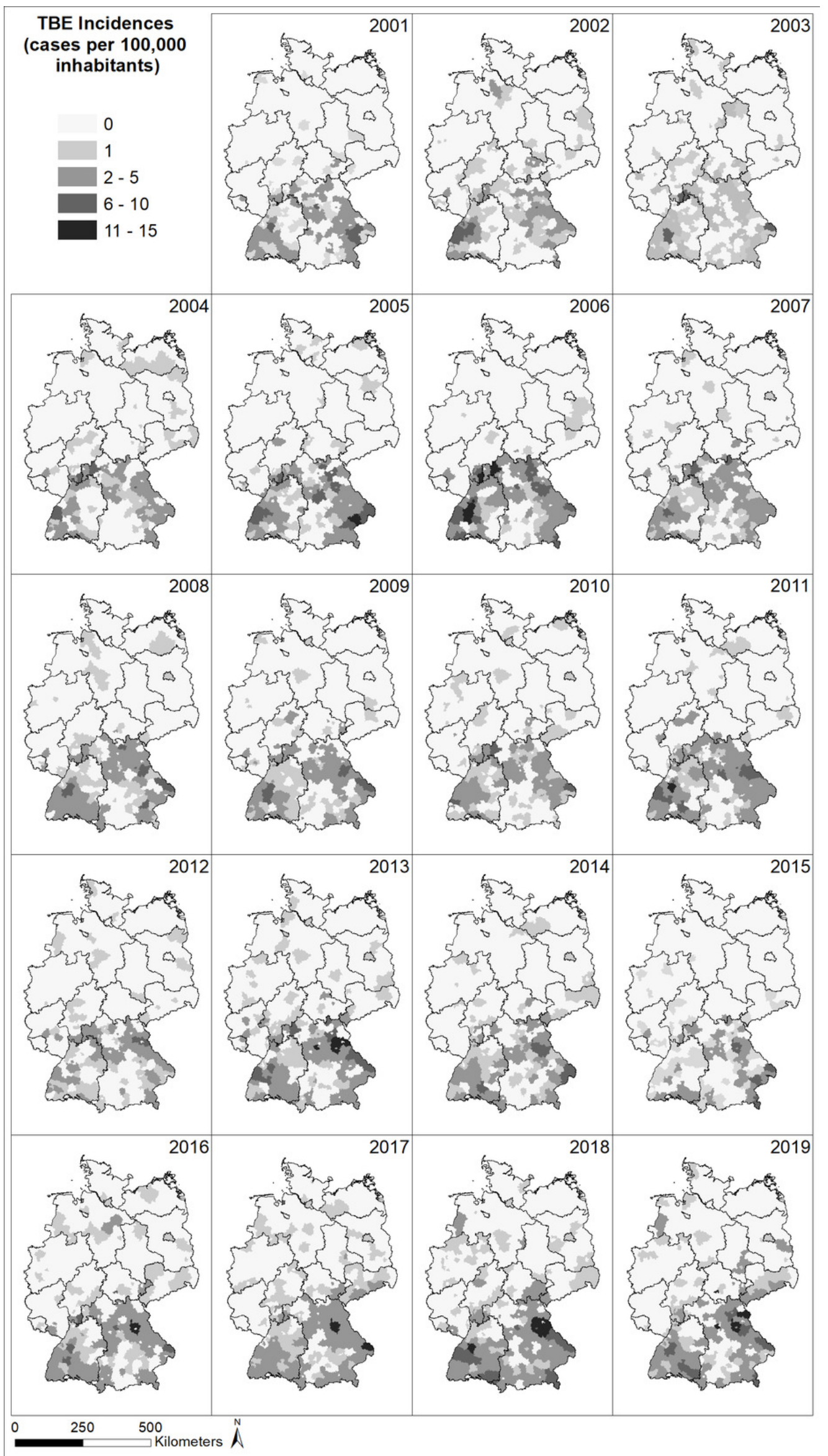


Figure 3

Spatial patterns of incidences (reported cases per 100,000 inhabitants) for Lyme borreliosis (LB) at the level of German administrative districts (RKI data). 


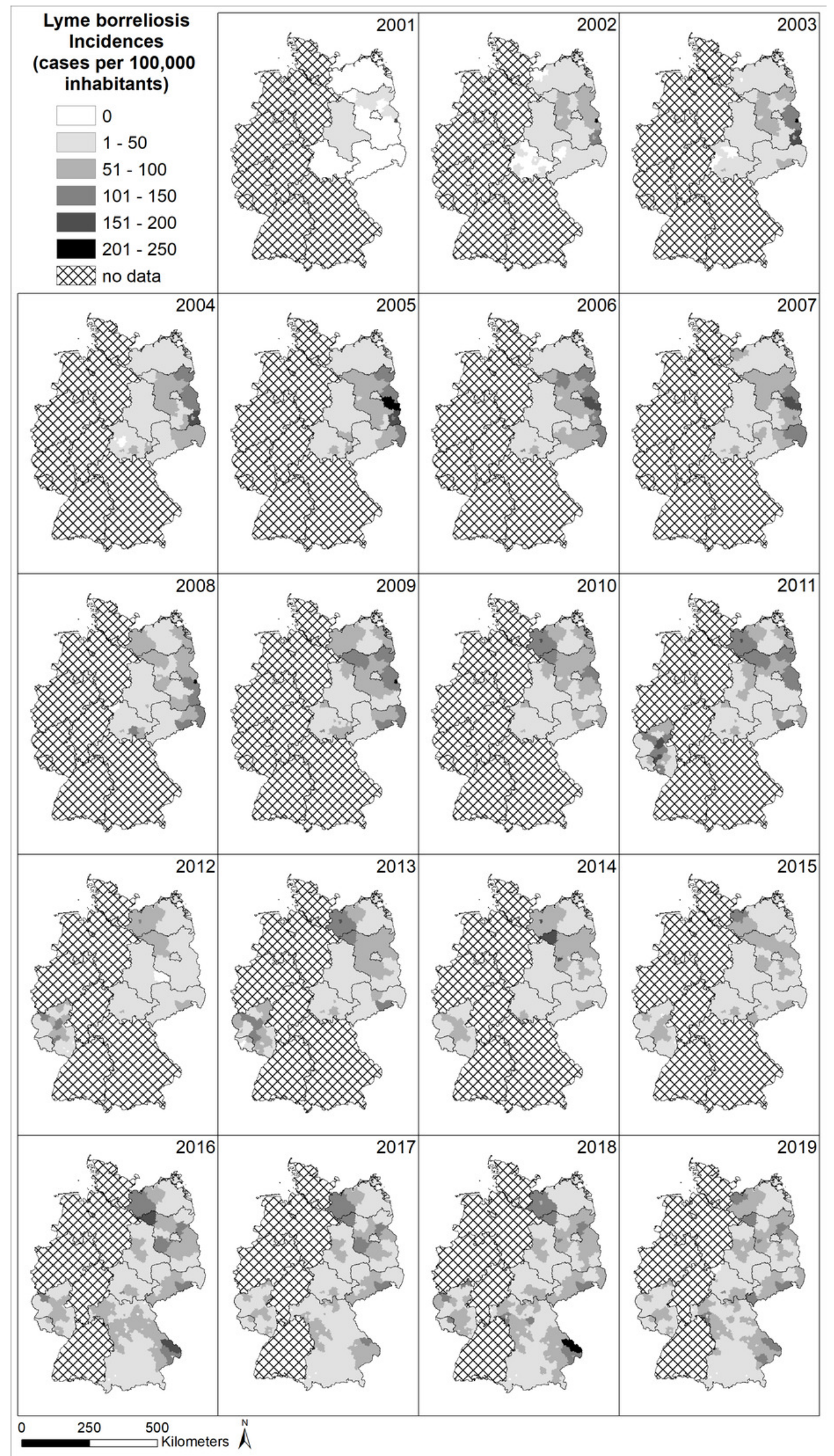

PeerJ reviewing PDF | (2021:02:58328:2:0:NEW 9 Oct 2021) 


\section{Figure 4}

Spatial patterns of tick-borne diseases, and associated environmental factors.

4a) Sum of recorded human TBE cases at a spatial level of German administrative districts between 2002 and 2019 (RKI data); 4b) Sum of recorded human LB cases at a spatial level of German administrative districts between 2002 and 2019 (RKI data); 4c) number of inhabitants (RKI data). 4d) occurrence records for Ixodes ricinus (GBIF data) and areas with known presence of I. ricinus (ECDC); 4e) distribution of wild boar (WILD data DJV); 4f) annual precipitation $\mathrm{mm}$ ] (DWD data); 4g) annual mean temperature [ $\left.{ }^{\circ} \mathrm{C}\right]$ (DWD data); 4h) percentage forest cover (Corine land cover data) 


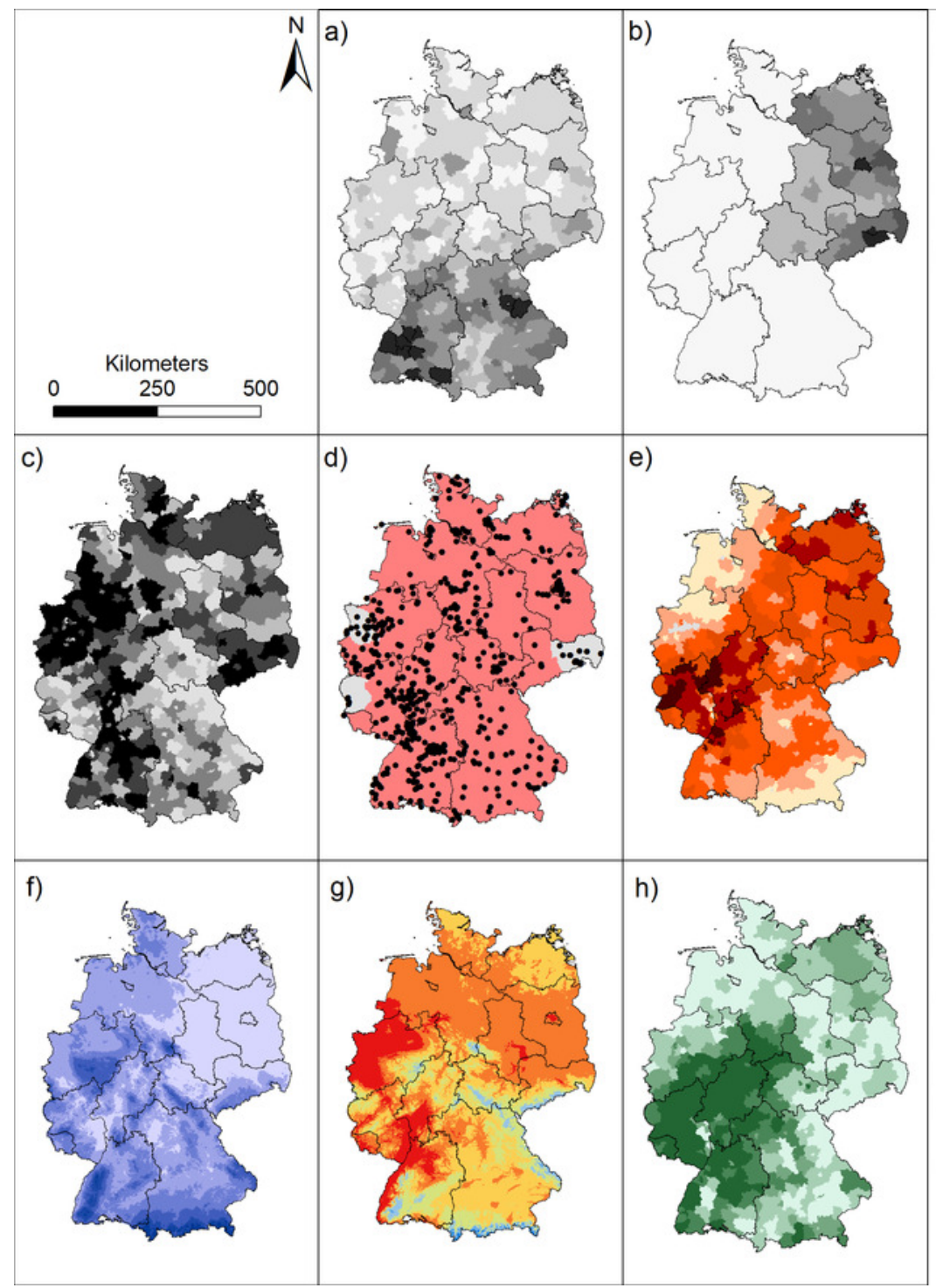

(a) recorded TBE cases (sum over 2002 - 2019)

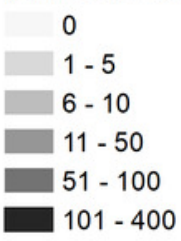

(c) number of inhabitants

$34270-96164$

$96165-132006$

$132007-183256$

$183257-262405$

$262406-3613495$

(e) host distribution Sus scropha

$$
\begin{aligned}
& >0.00-0.25 \square>2.00-3.00 \\
& >0.25-0.50 \square>3.00-4.00 \\
& >0.50-1.00 \square>4.00-6.74 \\
& >1.00-2.00 \square \text { no data }
\end{aligned}
$$

(f) annual precipitation (DWD) mean over 1981 - 2010
$\square 06-692 \square 1082-1424$
$693-864 \square 1425-1928$
$865-1081 \square 1929-3324$

(g) annual mean temperature (DWD) mean over 1981 - 2010

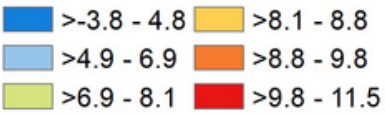

(h) percentage of forest area (CLC 2012)

$<5 \quad 15-25$
$5-10 \square>25$
$10-15$




\section{Figure 5}

Temporal patterns of the recorded human tick-borne diseases cases between 2002 and 2019 in relation to the main components in the transmission cycle and associated environmental factors.

a) Sum of recorded human TBE cases in Germany per month (RKI data); b) Sum of recorded human LB cases in the six federal states with a continuous reporting obligation since 2002 (Brandenburg, Berlin, Mecklenburg-Vorpommern, Saxony, Saxony-Anhalt and Thuringia) per month (RKI data); c) Recorded human TBE cases in Germany per year (RKI data); b) Recorded human LB cases in the above mentioned six federal states per year (RKI data) e) monthly mean temperature $\left[{ }^{\circ} \mathrm{C}\right]$ (DWD data); f) monthly precipitation sums [mm] (DWD data); $4 \mathrm{~g}$ ) beech mast: percentage of trees with strong fructification mean over data of five federal states (WZB, 2018a, 2018b, 2019a, 2019c, 2019b) 


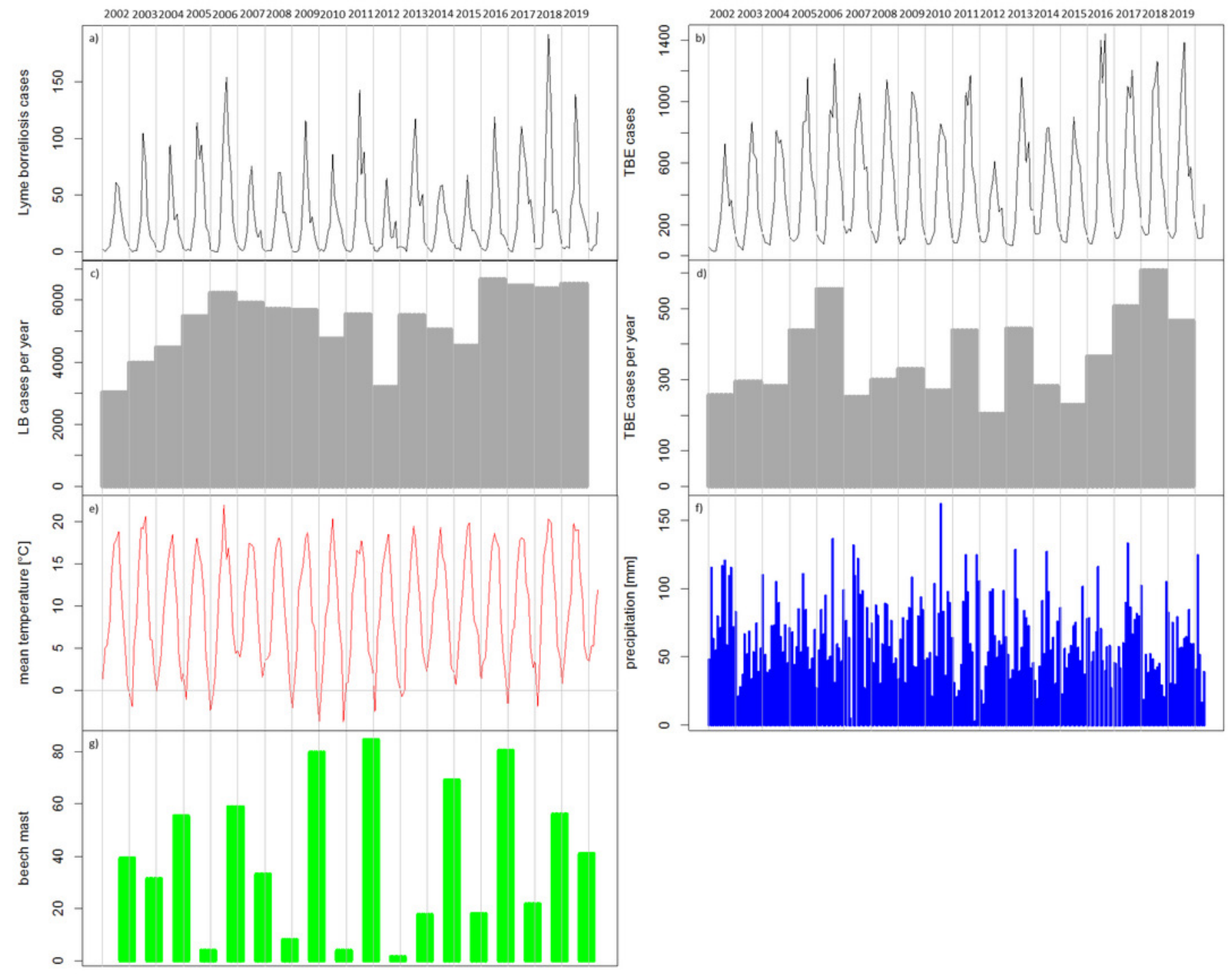




\section{Figure 6}

Relation between Numbers of reported disease cases of TBE and LB between 2002 and 2019.

Scatterplot of the reported cases reported in Germany for TBE and in the six federal states with a continuous reporting obligation since 2002 (Brandenburg, Berlin, MecklenburgVorpommern, Saxony, Saxony-Anhalt and Thuringia) for LB (to ensure comparability of the data) with a temporal resolution of a) one year and b) one month, respectively. Pearson correlation coefficient $r=0.71(p<0.001)$ for the annual data and $r=0.85(p<0.001)$ for the monthly data. RKI data. 
a)

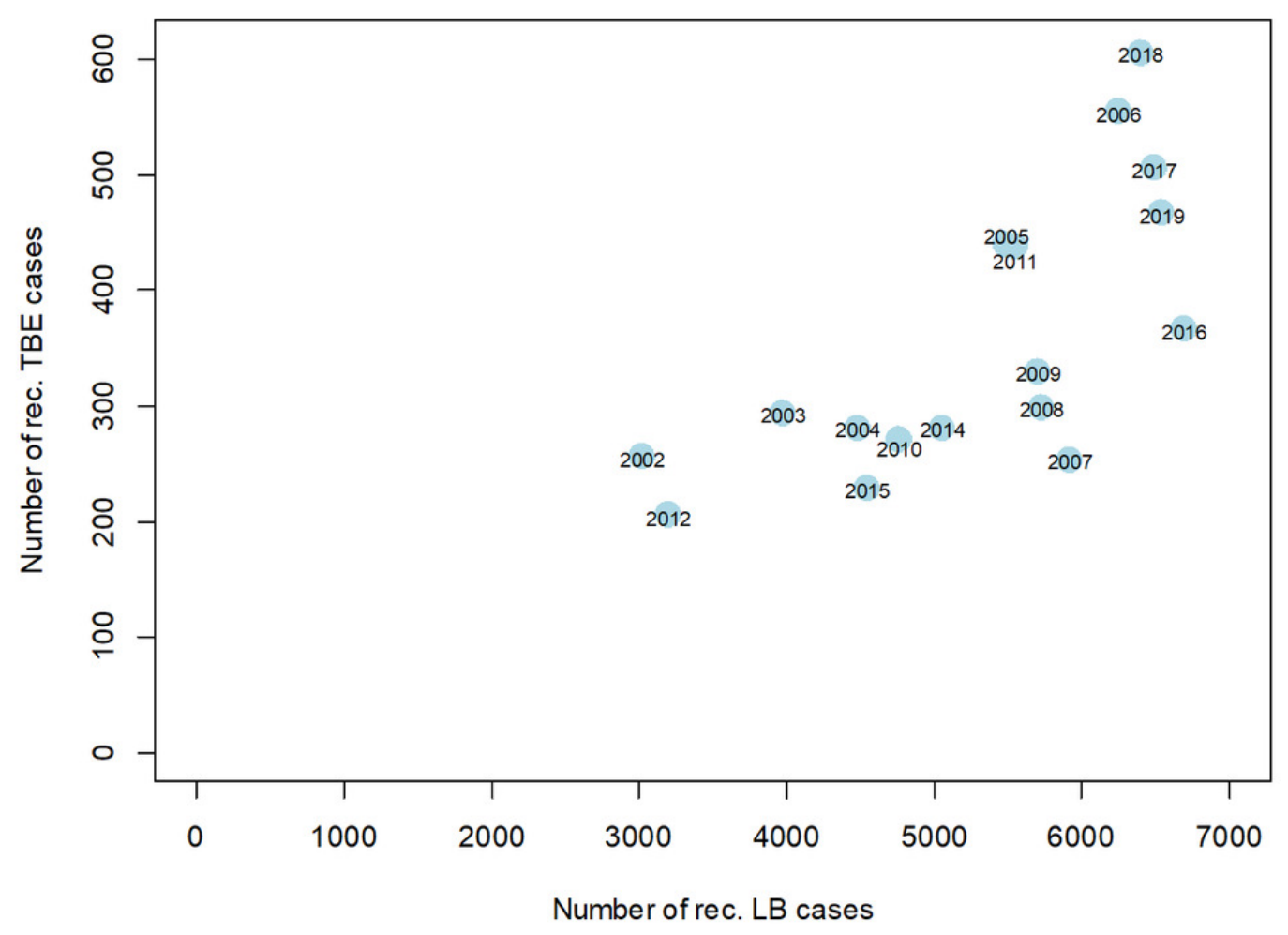

b)

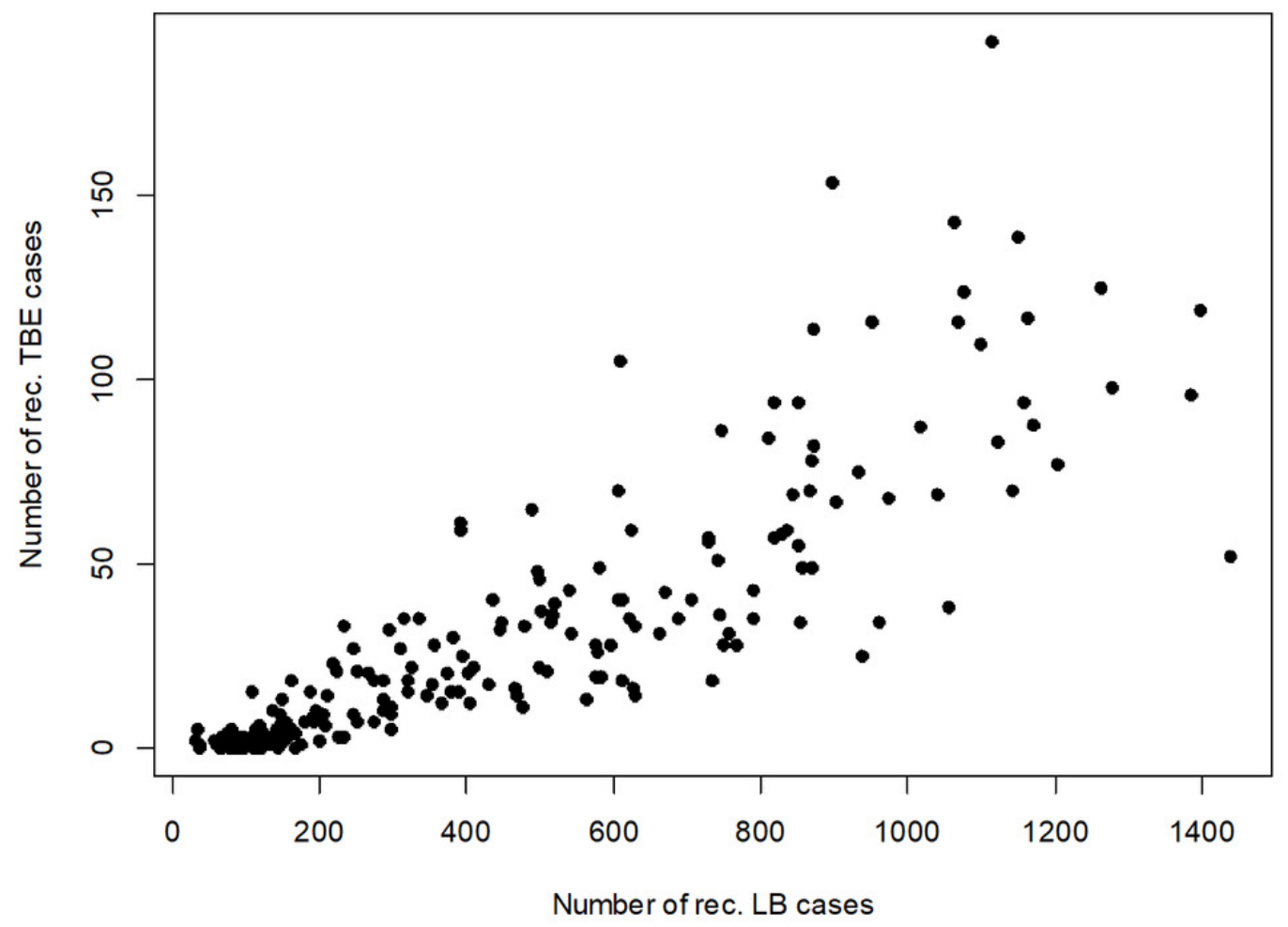

Peer] reviewing PDF | (2021:02:58328:2:0:NEW 9 Oct 2021) 
Figure 7

Numbers of recorded TBD cases related to gender and age.

a) Numbers of reported LB cases; b) Numbers o reported TBE cases (RKI data). 
a)

LB incidences

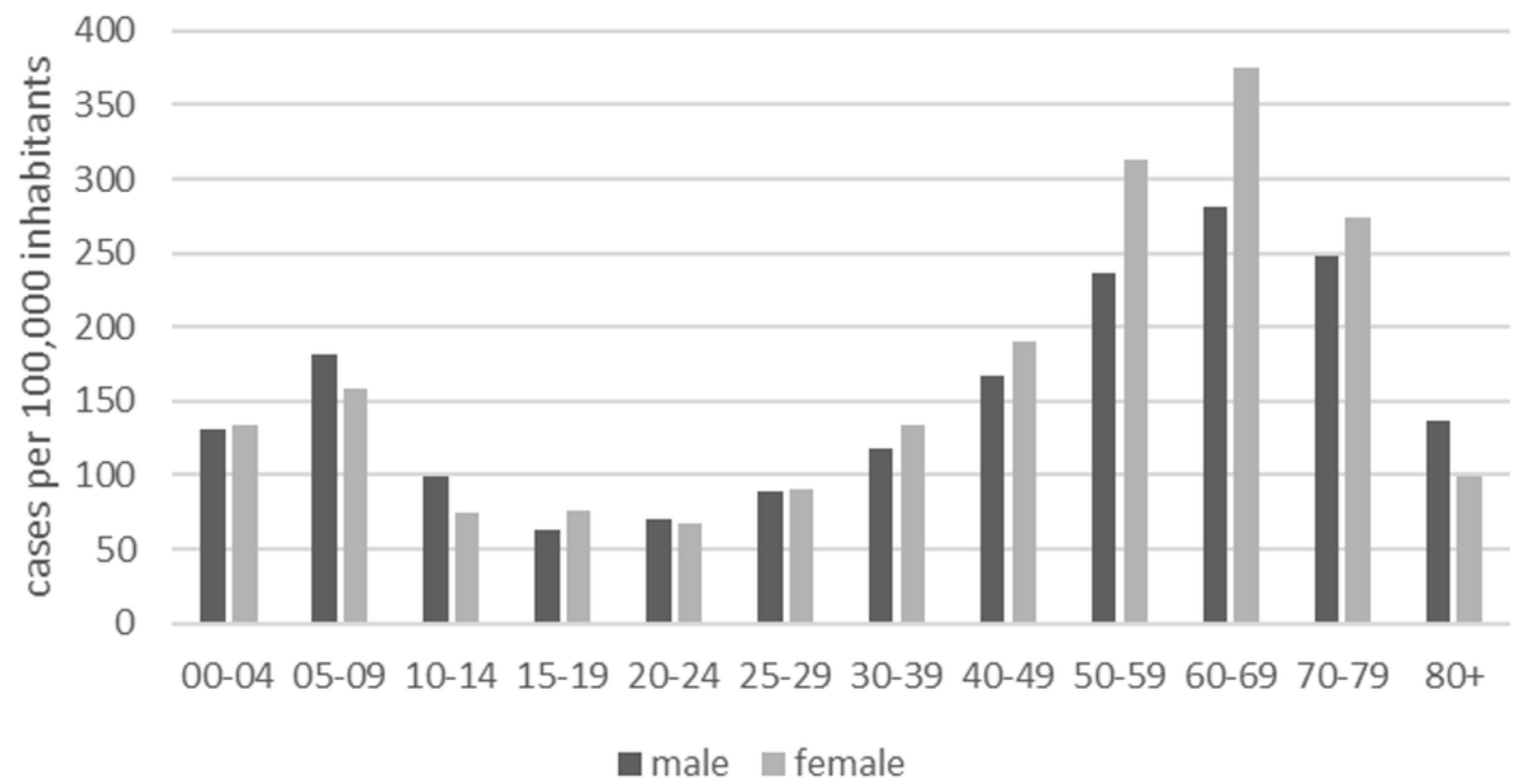

b)

\section{TBE incidences}

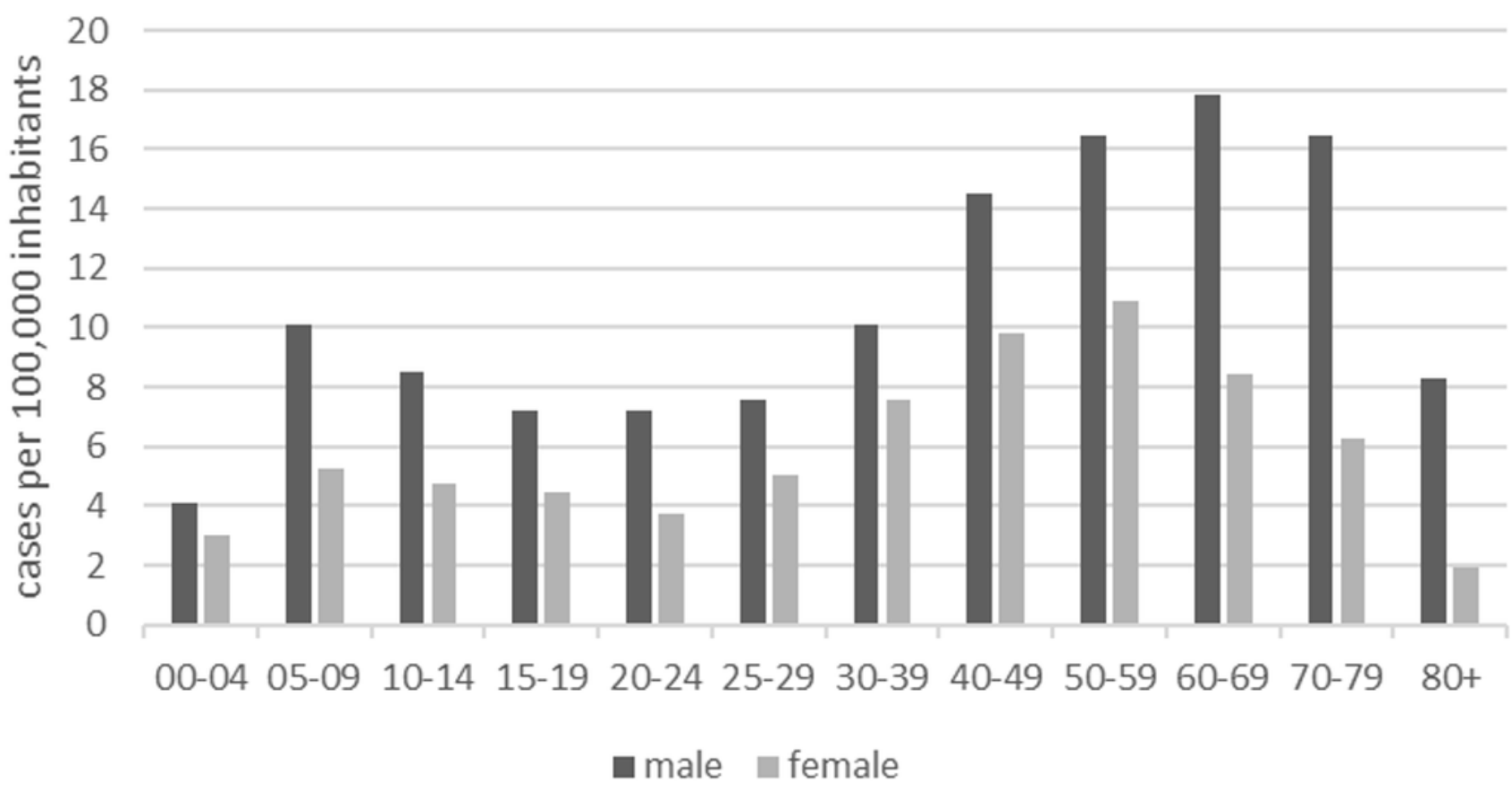

